\title{
KANT E A ADMIRAÇÃO DA NATUREZA
}

Ulisses Razzante VACCARI ${ }^{1}$

- RESUMO: O parágrafo 62 da Crítica do Juízo, cuja função é definir o conceito de conformidade a fins objetiva (objektive Zweckmässigkeit), começa com uma declaração do filósofo segundo a qual todas as figuras geométricas se relacionam com uma conformidade a fins objetiva e admirável. Embora não seja aqui essencial para a definição do princípio dessa conformidade a fins, a afirmação de Kant de que ela é muitas vezes digna de admiração exerce um importante papel para a sua própria definição. O objetivo deste texto é tecer algumas considerações em torno dessa relação entre o princípio estritamente lógico da conformidade a fins e o sentimento em geral, seja de admiração da natureza, ou em todas as suas variações, tais como aparece na sequência do mesmo parágrafo 62: o entusiasmo, a alegria e a estupefação. Embora de antemão se reconheça que tais sentimentos não podem intervir no mecanismo estritamente lógico desse princípio, que, segundo Kant, é transcendental, pretende-se mostrar como o seu uso relaciona-se sempre e de algum modo com um sentimento. Para isso, é preciso mostrar que a afirmação de Kant segundo a qual o juízo teleológico não possui nenhuma relação com o sentimento de prazer e desprazer não implica necessariamente que esse tipo de juízo não possua relação nenhuma como nenhum tipo de sentimento.

- PALAVRAS-CHAVE: admiração; sentimento; princípio; conformidade a fins.

Como o químico, é pela dissolução que o filósofo encontra a unidade, é pelo tormento da arte que encontra a obra da natureza espontânea. Para apreender a aparência fugaz, ele tem de fixá-la aos grilhões da regra, descarnar seu belo corpo em conceitos e conservar seu espírito vivo numa precária carcaça verbal. Espanta ainda que já não se reconheça o sentimento natural numa tal cópia e que a verdade pareça um paradoxo no relato do analítico?

(Schiller)

1 Doutorando em Filosofia pela Universidade de São Paulo e bolsista Fapesp. 
Kant abre o parágrafo 62 da Crítica do Juízo, cuja função é definir o conceito de conformidade a fins objetiva, do seguinte modo: "Todas as figuras geométricas que são desenhadas segundo um princípio [Prinzip], mostram uma conformidade a fins objetiva, múltipla e muitas vezes admirável [bewunderte]". ${ }^{2}$ O presente texto tem como objetivo, a partir disso, tecer algumas considerações acerca dessa ligação do sentimento de admiração com o princípio teleológico do juízo, que Kant denomina conformidade a fins objetiva. Muito embora este texto se circunscreva apenas ao sentimento de admiração pela natureza, o próprio Kant, ao se referir ao juízo teleológico no texto citado do parágrafo 62 , não se restringe a este sentimento apenas. Menciona, além da admiração, o entusiasmo, o prazer, o fervor e a estupefação. O enigma a compreender aqui, então, é por que o filósofo rechaça, na introdução à Crítica do Juízo, toda e qualquer relação do juízo teleológico com o sentimento de prazer e desprazer, o qual seria próprio do juízo estético e, todavia, ao abrir a parte concernente à teleologia, realiza uma antropologia filosófica do sentimento em toda sua possível relação com o referido princípio teleológico do juízo. Tendo, num primeiro instante respondido a isso, o presente texto tentará mostrar em que consiste essa relação do sentimento de admiração com esse mesmo princípio, denominado conformidade a fins objetiva.

\section{I}

A certa altura da segunda introdução à Crítica do Juízo, Kant afirma que a conformidade a fins da natureza (objetiva), "já que relaciona a forma do objeto, não às faculdades de conhecimento do sujeito na apreensão do mesmo, mas a um determinado conhecimento do objeto sob um conceito dado, não tem nada que ver com um sentimento de prazer [Gefühle der Lust] nas coisas, mas sim com o entendimento no julgamento das mesmas" (KU B XLIX). Com isso, toda possibilidade de se falar em sentimento de prazer no caso do juízo teleológico parece estar decididamente interditada, já que, neste, a relação entre entendimento e razão é estritamente lógica. Tal constatação, por sua vez, faria com que esse tipo de juízo pertencesse ou fosse filiado de alguma forma à parte teórica da filosofia transcendental, pois, como diz Kant: "a faculdade teleológica [...] procede, como sempre

2 KANT, I. Kritik der Urteilskraft. Suhrkamp Verlag: Frankfurt am Main, Herausgegeben Wilhelm Weischedel, Band X, 1974, p.271. A partir daqui, todas as referências à Crítica do Juízo de Kant serão indicadas apenas pela sigla do título original KU, seguida da letra B para indicar a segunda edição da obra (1793) e da paginação do original. Todas as citações retiradas dessa obra foram por mim traduzidas. 
acontece no conhecimento teórico, segundo conceitos" e "segundo sua aplicação, pertence à parte teórica da filosofia..." (KU B LII). Não obstante isso, a filiação desse juízo à teoria não se mostra assim tão simples. Se por um lado ela é possível, na medida em que a faculdade do juízo permite que as ideias da razão possuam um uso regulativo referente aos conceitos puros do entendimento, por outro, a razão só o faz na medida em que procura realizar essas ideias e encontrar para elas um fundamento efetivo na experiência. Como essa última condição de fato não se realiza, pois o entendimento a certa altura já não dá conta de acompanhar a razão nessas suas pretensões, esta abdica de sua procura pelo fundamento objetivo e se resigna ao âmbito meramente subjetivo que pertence a ela de direito. Nesse ponto opondo-se ao conhecimento, no qual as facdades subjetivas são dispostas em função da objetivação de um dado sensível, no juízo meramente teleológico ocorre um descompasso entre aquilo que exige a razão e aquilo que o entendimento pode determinar de modo finito em sua relação com o que é sensivelmente dado. O próprio campo do juízo reflexionante é definido, diante desse descompasso, como aquele no qual a razão se satisfaz com representações meramente subjetivas. Como diz Kant numa passagem lapidar de um texto de 1786 chamado O que significa orientar-se no pensamento?: "agora [...] entra o direito da necessidade da razão [das Recht des Bedürfnis der Vernunft], como um fundamento subjetivo para pressupor e admitir algo que ela não pode pretender saber através de fundamentos objetivos e, consequentemente, para, em pensamento, orientar-se tão-somente por sua própria necessidade no espaço do supra-sensível, incomensurável e para nós repleto de densa noite" (Kant, 2004, p.26).

Além de tudo, isso parece responder ainda e ao mesmo tempo a pergunta de como é possível associar qualquer tipo de sentimento a um princípio objetivo que, segundo Kant, se filia à parte teórica da filosofia transcendental. Como o juízo teleológico procura fundamentar ideias no plano meramente subjetivo da razão, isso, por si só, torna plausível sua associação com um sentimento, na medida em que este se assenta igual e necessariamente num plano subjetivo. Essa ideia, de acordo com a qual a razão pode se satisfazer a si mesma ao abdicar da procura de correlacionar suas representações com objetos dados sensivelmente, é fixada no mesmo texto de 1786 (O que significa orientar-se no pensamento?). Nele, utilizando-se de uma metáfora geográfica, Kant atesta ser possível orientar-se em terras desconhecidas sem a necessidade dos objetos exteriores; nesse caso específico, independentemente das estrelas. E assim, "se algum dia, por um milagre, todas as constelações, mesmo mantendo ademais a mesma figura e a mesma posição relativa mudassem apenas sua direção, tornando-se agora oeste a que antes fora leste, então, na próxima noite estrelada, certamente nenhum olho humano notaria a mínima mudança, e até mesmo o astrônomo 
inevitavelmente se desorientaria, se prestasse atenção somente ao que vê e não ao mesmo tempo ao que sente" (Kant, 2004, p.23). No plano do meramente subjetivo, no qual não se pode contar apenas com os objetos em redor, o sentimento serve de fio condutor para a razão se orientar no infinito mundo dos objetos empíricos.

Por esse motivo, embora Kant procure mostrar, num primeiro momento, que o sentimento de prazer e desprazer, tal como é apresentado no caso do juízo de gosto, não pode ter nenhuma relação com o juízo teleológico, isso se dá apenas num intuito de definir mais exatamente este último, não somente em suas diferenças com o juízo estético, mas, sobretudo, naquilo em que ele se assemelha ao juízo determinante. Como se verá essa semelhança com a filosofia teórica se incrusta na própria definição do juízo teleológico, e apenas um exame mais aprofundado, isto é, uma investigação transcendental, poderia desfazer o engano de, a partir de uma mera semelhança, tomar um pelo outro como se fossem o mesmo. Por conseguinte, somente uma investigação transcendental poderia desfazer o engano, já secular, de tomar o meramente heurístico pela própria efetividade da natureza. Se é possível distinguir um domínio do outro, aparentemente tão semelhantes entre si, esta distinção repousa justamente naquilo que Kant parecia não conceder ao juízo teleológico, a saber, na ligação deste com um sentimento, não de prazer e desprazer, como no juízo estético, mas com um sentimento particular de prazer e de admiração pela natureza, que inexistem no caso do mero conhecimento.

De fato, o simples encontro das percepções com as leis do entendimento não pode ser causa de nenhum prazer, pois a faculdade do juízo não lida nesse caso com a realização do conceito de fim, isto é, não vê realizar-se na natureza a chamada causalidade final. No ato de conhecer, trata-se de conduzir uma multiplicidade dada a um conceito igualmente dado, de modo que é essa predeterminação do conceito o que elimina a possibilidade de qualquer prazer e de qualquer sentimento. Ao se conhecer a natureza, o trabalho da faculdade do juízo (Urteilskraft) resume-se a subsumir objetos dados na intuição pura sob conceitos universais e necessários do entendimento, porque esses conceitos são determinantes dessa sua mesma função. Nessa relação, a faculdade do juízo não sente a liberdade necessária que ela mesma experimenta no juízo de reflexão; essa liberdade que permite uma relação mais estreita com a própria razão e que, segundo Kant, procede a um indispensável "alargamento do ânimo, como que para este pressentir algo que está acima daquelas representações sensíveis..." (KU B 277). Embora, assim, a finalidade possa ser de algum modo pressuposta no ato do conhecimento, sua função é reduzida a uma regulação da atividade do entendimento, e é substituída pela relação determinante deste último com a natureza, pela qual ele a conhece em sua máxima necessidade. Isso 
impossibilita de antemão o vigor de uma legislação subjetiva da razão e, como conseqüência, qualquer relação de prazer.

"Por outro lado - e aqui eu cito um texto da segunda introdução à Crítica do Juízo - a descoberta de que é possível unir duas ou várias leis empíricas da natureza sob um único princípio, que as engloba, é razão para um prazer digno de nota [eine sehr merkliche Lust], muitas vezes até de uma admiração infinita [eine Bewunderung ..., die nicht aufhört], mesmo que se esteja bastante familiarizado com o objeto desta"(KU B XL, grifos meus). Tal afirmação, em toda a sua força retórica, parece finalmente não deixar dúvidas de que esse procedimento da faculdade do juízo, segundo o qual ela procura, por meio de um princípio, uma representação mais universal para leis empíricas múltiplas, associa-se sempre a um sentimento de prazer. Se pode, assim, diferenciar o juízo teleológico do juízo de conhecimento, essa diferença estaria, sobretudo, ali onde o mesmo juízo teleológico se distingue do próprio juízo estético, a saber: no fato de que o sentimento de prazer associado ao primeiro não é um sentimento em geral de prazer e desprazer, mas, pelo contrário, um prazer digno de nota e uma admiração sem fim.

\section{II}

Entretanto, pelo que segue essa relação do juízo teleológico com o conhecimento, ou a sua filiação a ele, apresenta consequências nefastas para a consideração do sentimento de prazer e de admiração. Como afirma o texto da segunda introdução, apesar de ser possível observar uma relação do uso do juízo teleológico com um prazer, "na verdade, nós já não pressentimos mais qualquer prazer notável ao apreendermos a natureza e a sua unidade da divisão em gêneros e espécies, coisa unicamente pela qual são possíveis conceitos empíricos, por meio dos quais a conhecemos em suas leis particulares" (KU B XL). Que a causa disso esteja justamente na semelhança ou mesmo confusão do juízo teleológico com o juízo determinante, que Kant não deixa de mencionar, é o que se deduz. Mas, nesse ponto, essa semelhança é apresentada a partir de uma perspectiva histórica, a partir da qual é possível observar a decadência do princípio do prazer em sua relação com o princípio do julgamento teleológico, na medida em que este pareceu aos poucos se incorporar pelo uso ao uso da mesma faculdade do juízo, mas em sua destinação ao conhecimento. Segundo essa perspectiva histórica assumida pelo texto da segunda introdução e pelo próprio parágrafo 62 , se na antiguidade era notável o prazer que a investigação da natureza proporcionava, nesse sentido de constituir uma investigação indeterminada de leis meramente empíricas, isso foi ao longo do tempo desaparecendo até que, na era moderna, sumiu quase por completo. Segundo Kant, a tendên- 
cia de enfatizar cada vez mais o conhecimento, no sentido próprio que esse termo adquiriu na filosofia e nas ciências modernas, levou, consequentemente, a uma subjugação de tudo aquilo que, pelo contrário, deveria ser descartado justamente por não pertencer a esse domínio. Deixado de lado por pertencer à esfera do meramente subjetivo, psicológico e empírico, isso que a filosofia transcendental chama de princípio da conformidade a fins objetiva passou a um segundo plano na hierarquia dos saberes da modernidade, em cujo topo figurava sobranceiramente apenas o conhecimento puramente racional, isto é, aquele que trazia em si as exigências do absolutamente universal e necessário. Como consequência disso, o prazer que, segundo Kant, associa-se a esse princípio do chamado juízo teleológico, o qual os filósofos e geômetras antigos utilizavam sem se dar conta, isto é, inconscientemente, também desapareceu nessa nova relação do homem com a natureza, pois, em seu lugar, passou a dominar apenas a fria relação lógica entre conceitos.

Essa ideia, tal como ela aparece no seguinte texto da introdução, é suficientemente clara: “...certamente conheceu-se esse prazer em outros tempos e somente porque a experiência mais comum não seria possível sem ele, foi gradualmente se misturando com o mero conhecimento, sem se tornar mais especialmente notado. - Por isso faz falta algo que torne o nosso entendimento atento à conformidade a fins no julgamento da natureza, um estudo que conduza as leis heterogêneas da mesma, onde for possível, sob outras leis superiores, mesmo que continuem a ser empíricas, para sentirmos prazer nesta sua concordância com as nossas faculdades de conhecimento..." (KU B XL, grifo meu). Claramente relacionado ao princípio do juízo teleológiCo, esse raciocínio expressa a abrangência da filosofia kantiana que, muito além de se restringir apenas às exigências de legitimação do conhecimento racional, pretendeu dar conta também daquilo que de algum modo não poderia se encaixar nesse ideal. Segundo esse raciocínio de Kant, uma tendência constante e crescente para reduzir a razão - esse universo complexo e admirável - a um único uso, fez com que qualidades suas nem sempre redutíveis, entretanto se reduzissem e de certo modo se perdessem. Essas qualidades, nesse caso as características teleológicas de julgar, que não aspiram à universalidade e necessidade absolutas dos conceitos de entendimento, referem-se a essa sua capacidade de lidar livremente com gêneros e espécies da natureza de acordo com o mais genuíno prazer que isso ocasiona.

O texto citado evoca, assim, a necessidade de desenvolvimento de uma investigação filosófica que dê conta da precisa delimitação do campo de uso do princípio teleológico, em toda sua distinção do domínio do puro conhecimento, na medida em que, por lidar com leis empíricas e com fundamentos subjetivos, não é por isso menos digno de nota; não é porque não se trata de um conhecimento de mesmo grau que aquele proporcionado 
pelo entendimento que ele não mereça uma investigação de delimitação de seu domínio e de sua legislação própria. Se existe um uso da faculdade do juízo que, apesar de não se definir como conhecimento, permita orientar a razão num campo homogêneo de leis empíricas, lá onde o próprio conhecimento já não pode mais atuar e não possui mais eficácia, estaria delimitado o campo de atuação e a legislação de um princípio ainda desconhecido da própria razão.

Se, assim, em alguns textos Kant enfatiza a semelhança e a filiação do juízo teleológico à filosofia teórica, em outros essa semelhança passa a ser diminuída. Se, na delimitação do domínio do juízo teleológico, encontra-se uma relação dele com um sentimento é porque existe algo de peculiar nesse juízo que o distingue do mero conhecimento da natureza. Como se viu pelo texto do opúsculo de 1786, essa peculiaridade estaria no fato de que agora entra em jogo uma necessidade ou, mais propriamente, uma carência (Bedürfnis) da razão que, no conhecimento, permanecia oculta à medida que, nele, o entendimento assumia o primeiro plano na relação do ânimo com a natureza. Agora, nesse plano reflexionante do juízo teleológico, é a relação da razão com a natureza que passa a primeiro plano e essa relação é expressa pela sua necessidade infinita de procurar um fundamento para o infinito mundo fenomênico. A função da faculdade do juízo, nesse plano, é então satisfazer a razão nessa sua carência, por meio daquilo que Kant denomina de técnica da natureza. De acordo com esse princípio, o juízo sacia essa necessidade incessante da razão, pois, nele mesmo e segundo sua legislação própria - isto é, segundo uma técnica - encontra um fundamento supra-sensível como o termo, o fim do à primeira vista infinito mundo de leis empíricas. Essa limitação da causalidade antes infinita proporciona à razão uma homogeneização da própria natureza, motivo pelo qual ela consegue, a partir disso, se orientar nela. Ora, é então desse modo que um sentimento de prazer e uma admiração da natureza acompanham sempre esse uso da faculdade do juízo, na medida em que surgem do preenchimento de uma carência, de uma necessidade de encontrar um termo para o infinito mundo da causalidade da natureza.

No parágrafo 62 da Crítica do Juízo, Kant percorre esse mesmo caminho e dá uma ênfase especial justamente na relação da admiração com a técnica do juízo, também denominado de princípio heurístico. Segundo esse texto, "[...] é na necessidade daquilo que é conforme a fins e constituído como se [als ob] fosse disposto intencionalmente para o nosso uso, parecendo, entretanto, convir originalmente ao ser das coisas sem se referir a esse uso, que reside precisamente a razão da grande admiração da natureza, não tanto fora de nós quanto na nossa própria razão..." (KU B 273-4, grifo meu). Sem o caráter heurístico do princípio da conformidade a fins objetiva, que permite pôr um termo na causalidade fenomênica, não é possível ao juí- 
zo teleológico enxergar a natureza de um modo homogêneo, derivar leis universais de leis mais particulares, e assim experimentar qualquer sentimento nessa sua investigação. Não fosse possível à razão, por meio de uma técnica do juízo, pôr-se nessa ótica finalística da natureza, jamais poderia ela conhecer suas leis mais particulares e, quem sabe, sequer admirá-la. A conformidade a fins atribuída ou descoberta na natureza pela faculdade do juízo deve, assim, parecer convir "originalmente ao ser das coisas". E é para entender o que significa isso, que Kant fornece o exemplo de Platão. Segundo Kant: "Platão [...] - ao deparar com essa constituição original das coisas (que, para ser descoberta, implica podermos afastar toda experiência) [...] entrou num entusiasmo [Begeisterung] que o ergueu até ideias, acima dos conceitos de experiência, que somente se lhe puderam ser explicadas por meio de uma comunidade intelectual [intelektuelle Gemeinschaft] com a origem de todos os seres. Não é, pois, uma surpresa que ele tenha expulsado da sua escola os desconhecedores da arte de medir, na medida em que pensava deduzir da intuição pura, no íntimo do espírito humano, aquilo que Anaxágoras deduziu dos objetos da experiência e da respectiva ligação final" (KU B 273-4).

O filósofo ateniense, num pleno uso da técnica do juízo em sua função teleológica, alcançou assim uma unidade no campo já tornado homogêneo da natureza, e com isso, influenciado por aquela necessidade da razão, entusiasmou-se a ponto de convencer-se que esse caminho o conduziria a conhecer a natureza em seu próprio ser. Sem suspeitar de que se tratava de um princípio cujo uso era apenas heurístico, o autor do Sofista aplicou-o indistintamente à natureza numa tentativa de revelar a sua essência, de modo que, para fornecer um fundamento mais sólido dessa sua empreitada, teve de recorrer a uma comunidade intelectual com a origem de todos os seres. Geômetra incorrigível, o erro de Platão, segundo Kant, foi ter pretendido deduzir os fins, que, como se viu, são conceitos da razão, da intuição sensível pura. Pois, tal como no juízo teleológico, também na geometria o ânimo procede de modo completamente indeterminado, isto é, sem saber de antemão que uma lei ou um princípio em particular pode possuir uma utilidade desconhecida, para a resolução de problemas que sequer foram ainda formulados, e que apenas o tempo poderia mostrar. É desse modo que "as propriedades da parábola eram por [esses geômetras] estudadas, sem conhecerem a lei da gravidade da Terra, lei que lhes teria fornecido a aplicação da mesma à trajetória dos graves..." (KU B 273). Ou então: "É, por exemplo, o que acontece quando se constrói um triângulo a partir da base e do ângulo oposto. Nesse caso, o exercício é indeterminado, ou seja, é possível resolvê-lo de infinitas maneiras. [Mas] só o círculo contém todas as soluções na sua globalidade, na medida em que é o lugar geométrico para todos os triângulos que satisfazem esta condição" (KU B 272). 
De fato, Platão parecia proceder dessa forma em suas investigações, porém indistintamente em relação à geometria e àquilo que Kant diz ser o domínio do juízo teleológico. De acordo com o filósofo alemão, por ter deixado se levar pela semelhança que de fato há entre uma coisa e outra, e por ter pretendido derivar fins da própria natureza, como se eles fossem perceptíveis na intuição pura, o filósofo grego ultrapassou muitas vezes a simples admiração e, levado por um entusiasmo nem sempre benéfico, beirou a exaltação (Schwärmerei). Não obstante isso, diz Kant: “... é também perfeitamente compreensível e em verdade justificável o motivo da admiração de uma conformidade a fins, mesmo que percebida no ser das coisas [...]. As múltiplas regras, cuja unidade (obtida a partir de um princípio) leva a esta admiração, são no seu conjunto sintéticas [...]. Mas por isso é como se esta unidade parecesse ter empiricamente um princípio das regras exterior e diferente da nossa faculdade de representar e por isso o acordo do objeto com a necessidade das regras [...] é em si contingente [...]. Ora, justamente porque essa harmonia [...] não pode ser empiricamente conhecida, mas sim a priori, deveria conduzir-nos por si só à descoberta de que o espaço [...] não é uma qualidade das coisas fora de mim, mas sim em mim um simples modo de representação" (KU B 276).

É digna de admiração mesmo uma conformidade a fins que pretenda derivar esses fins da própria natureza. Pois, seja nesse caso em que por meio de uma investigação transcendental, perceba-se a impossibilidade de se derivar os fins do ser da natureza, isto é, por meio da intuição pura, o sentimento de admiração é o mesmo e indica já um uso da faculdade do juízo que não se enquadra naquele uso referente ao conhecimento. E embora Platão não tivesse observado essa distinção que separa a investigação teleológica da natureza da outra pertencente à geometria, o filósofo grego já empregava a faculdade do juízo com um objetivo muito semelhante àquele que Kant denominaria juízo teleológico e cuja legislação própria apenas a filosofia transcendental poderia encontrar. Segundo Kant, esse princípio é digno de provocar prazer e admiração, entusiasmo e mesmo alegria, porque o seu terreno, comum também à geometria, é o da indeterminação. Tal como na ciência de Euclides, embora tudo seja feito de acordo com um princípio a priori, permanece a impressão inevitável de se tratar de um procedimento meramente empírico, no qual as figuras ou leis encontradas o são apenas por uma extrema contingência. Mas é justamente nisso, diz Kant, que reside a possibilidade de qualquer prazer nesse tipo de investigação: na liberdade da comparação, da reflexão e da experimentação que constituem a essência desse tipo de princípio. E, nesse sentido, atesta o filósofo: "é uma verdadeira alegria [eine wahre Freude] observar o fervor com que os antigos geômetras investigavam estas propriedades destas linhas, sem deixar-se influenciar por perguntas próprias de espíritos limitados, como por exemplo: para que servirá afinal este conhecimento?" (KU B 272-3). 
VACCARI, Ulisses Razzante. Kant and nature admiration. Trans/Form/Ação. (São Paulo), v.32(1), 2009, p.85-94.

- ABSTRACT: Paragraph 62 of the Critique of Judgment, which was designed by Kant to define the concept of objective finality (objektive Zweckmässigkeit), begins with a statement of the philosopher, which says that all geometrical figures relates itself to a admirable and objective finality. Even though it is not key to defining the principle of this finality here, Kant's declaration that more often than not it is worth admiration plays a significant role in its very definition. The purpose of this paper is to discuss how the strictly logical principle of finality relates to general sentiment, either as admiration of nature or throughout the range of all of its variations, as subsequently shown in this very paragraph 62: Enthusiasm, joy, and stupefaction. Admittedly, such sentiments cannot intervene in the strictly logical mechanism of said principle, which is transcendental for Kant, still this paper will try to show how its usage relates to a sentiment at all times somehow. This requires showing that Kant's declaration that the teleological judgment holds no relation with the pleasure and displeasure sentiment does not necessarily imply that this type of judgment does not relate to any type of sentiment at all.

- KEYWORDS: admiration; feeling; principle; finality.

\section{Referências bibliográficas}

KANT, I. Kritik der Urteilskraft. Suhrkamp Verlag: Frankfurt am Main, Herausgegeben Wilhelm Weischedel, Band X, 1974.

O que significa orientar-se no pensamento. In: "Entre Kant e Hegel". EDIPUCRS: Porto Alegre, 2004, trad. Joãosinho Beckenkamp.

SCHILLER, F. A educação estética do homem - Numa série de cartas. Iluminuras: São Paulo, 1989, trad. Roberto Schwarz e Márcio Suzuki. 